\title{
Percurso para o Senado: carreiras e social background dos senadores das $51^{a}$ e $52^{a}$ Legislaturas ${ }^{1-2}$
} Alison Ribeiro Centeno ${ }^{3}$

\section{Resumo}

Analisando o Senado Federal entre 1999 e 2006, objetiva-se apresentar as características de recrutamento dos Senadores de acordo com o posicionamento de seus partidos no espectro ideológico esquerda-centro-direita. Estruturou-se um banco de dados com: titulação escolar, profissão prévia à carreira política, e os cargos institucionais eleitorais e nomeativos ocupados pelos 135 políticos que passaram pelo Senado durante o ínterim. Apresenta-se o período como composto por bacharéis, razoavelmente distintos em suas profissóes pregressas e um contraste na formação das carreiras políticas - alto nível de experimentação para políticos dos partidos de centro e direita, e menor experiência dos Senadores dos partidos de esquerda. ${ }^{4}$

Palavras-chave: Senado Federal. Carreiras políticas. Social background.

I Versão aprofundada de trabalho apresentado no II Seminário Internacional de Ciência Política (II SICP). Agradecimentos aos colegas do Grupo de Trabalho: Elites e poder judiciário, pelas críticas que enobreceram o trabalho.

2 Agradecimentos aos pareceristas pelas sugestões que geraram profundas reflexões e deram maior qualidade ao artigo através de suas colocações.

3 Atualmente, cursa Doutorado em Ciências Sociais (2019-2023) na Pontifícia Universidade Católica do Rio Grande do Sul (PUC- RS). Possui graduação em Ciências Econômicas (2011-2015) e Mestrado em Ciências Sociais (2016-20I8), também pela PUC-RS. Estágio na Fundação de Economia e Estatística (FEE) como bolsista de Iniciação Científica da Fundação de Amparo à pesquisa do Estado do Rio Grande do Sul (FAPERGS) (2013-2015), trabalhando com análise de indicadores; durante a pós-graduação, bolsista da Coordenação de Aperfeiçoamento de Pessoal de Nível Superior - Brasil (CAPES) (2016-2018), desenvolvendo estudos na área de recrutamento de elites políticas, com artigos publicados sobre eleições e teoria política. Atualmente, é revisor de periódicos na área de Ciência Política, na qual tem experiência de pesquisa com ênfase em carreiras políticas, eleições majoritárias e Senado Federal. E-mail: alison.centeno@edu.pucrs.br.

4 O presente trabalho foi realizado com apoio da CAPES - Código de Financiamento 001.

$(\infty)$ EY
Direito autoral e licença de uso: Este artigo está licenciado sob uma Licença Creative Commons. Com essa licença você pode compartilhar, adaptar, para qualquer fim, desde que atribua a autoria da obra, forneça um link para a licença, e indicar se foram feitas alterações. 


\section{Introdução}

O presente trabalho deriva da dissertação "Os maestros da elite: carreiras e trajetórias dos líderes no Senado Federal entre 1999 e 2006”. $\mathrm{Na}$ pesquisa anterior se buscou trazer luzes aos parcos estudos sobre a Casa da Federação, focando no social background, nas trajetórias e nas carreiras dos Senadores que compuseram as $51^{\mathrm{a}}$ e $52^{\mathrm{a}}$ Legislaturas, contrapondo esses perfis com os dos líderes no Senado Federal. A conclusão da escrita prévia foi que as lideranças das legendas e das bancadas suprapartidárias no Senado durante o período eram ainda mais experientes politicamente, com maior incidência de diplomas no ensino superior e de maior concentração das trajetórias predominantes encontradas no "corpo" da Casa.

Há consenso que o Senado é o ente legislativo por onde passam muitos dos mais experimentados políticos do País; porém, pouco ainda se foi explorado academicamente sobre sua dinâmica interna (NEIVA, 2011; ARAÚJO, 2011; CENTENO, 2018), considerando todas as prerrogativas constitucionais que a Câmara Alta tem no Brasil. Isto posto, combinado com os estudos que reforçam a preeminência do capital social e da experimentação política na eleição para o Congresso Nacional, invoca-se o estudo quanto à possível "padronização" ou "dissonância" do recrutamento dos partidos à Casa da Federaçáo de acordo com seus respectivos posicionamentos no espectro ideológico nesse importante período da história política do Brasil pós-redemocratização.

No constante digladiar entre situação e oposição, seja na fiscalização de atividades de instituiçóes, seja na sabatina de autoridades indicadas, na simbologia do embate político está a capacidade de impor o argumento prevalente. Passa pelo Senado Federal a conduta das temáticas basilares da estruturação de políticas de cada governo. Ao longo das próximas três seçóes, espera-se apresentar os padróes de recrutamento das legendas nos termos do social background - profissão e titulação escolar prévios ao mandato de Senador, e de carreira política - mandatos eletivos e nomeativos dos Senadores antes dos mandatos nas legislaturas em estudo.

Objetiva-se delinear as principais características de antecedentes à empreitada política e, após adentrar o meio político, quais cargos os Senadores ambicionaram na seara eleitoral até chegarem à representação federativa. 
As informações sobre diplomas e profissões, bem como cargos políticos prévios ocupados foram coletadas no Dicionário Histórico-Biográfico Brasileiro da Fundação Getúlio Vargas e nas minibiografias dos Senadores, no portal do Senado Federal.

Os partidos foram divididos na escala ideológica esquerda-centro-direita, de acordo com os parâmetros de Rodrigues (2009) e Power e Zucco Jr. (2009), sendo: esquerda (PCdoB, PT, PSB, PPS e PDT), centro (PSDB e PMDB) e direita (PTB, $\mathrm{PR}^{5}, \mathrm{DEM}$ e PP). Ao longo do período em estudo, dez partidos tiveram representação no Senado Federal, num total de 135 políticos que passaram pela Casa, titulares (113) e suplentes (22). Mesmo com o maior número de partidos, a esquerda foi a que menos teve acesso aos assentos da Câmara Alta (34 políticos), número menor que o conjunto de membros de partidos de direita (43); porém, ambos sobrepostos pelos Senadores filiados aos dois partidos de centro (58), algo que, na próxima subseção, será melhor tratado.

Após essa introdução, há um compêndio de levantamentos recentes sobre o social background do mainstream político nacional, prezando pelos estudos que mais se aproximam do ente legislativo, da esfera e do período que são escopos do presente trabalho. Por fim, retratam-se os padróes das carreiras institucionais dos Senadores, desaguando nas conclusóes que mostram um Senado de perfil coeso, ressalvadas idiossincrasias partidárias.

\section{Recrutamento de elites políticas}

Os estudos sobre elites políticas no Brasil avançam pelas mais diversas frentes: profissionalização política (COSTA; CODATO, 2012; MIGUEL, 2003; PERISSINOTTO; VEIGA, 2014), capital familiar (MIGUEL, MARQUES; MACHADO, 2015), social background (RODRIGUES, 2002, 2009; NEIVA; IZUMI, 2014; CORADINI, 2012) e trajetórias políticas (CORADINI, 2007) formam os principais mecanismos para entender a formação da elite parlamentar brasileira. Rodrigues (2002, 2009) e Gaxie (2012) sintetizam o entendimento que, majoritariamente, a classe

5 Extinto PL (partido que, posteriormente a fusão com o PRONA, tornou-se o PR). 
política, quando não é dotada de elevados recursos socioeconômicos, se distancia da maioria da população pelos recursos educacionais.

Muitos dos que "furam a fila" dos profissionais da política, coabitam no campo político (BOURDIEU, 2002) por fora dos meios institucionais e convertem capital social, midiático, religioso etc., (RODRIGUES, 2002, 2009; MIGUEL, 2003; CORADINI, 2007) em votos, pavimentando a chegada aos mandatos eletivos, estruturando capital político. Todavia, quanto mais elevado o posto, mais difícil para outsiders se valerem de recursos que os projetem ao campo político (MIGUEL, 2003; COSTA; CODATO, 2012).

Ao passo que nos partidos de direita e de centro há "uma posição social mais elevada", enquanto existe "uma tendência a posiçóes sociais médias e baixas nos partidos de esquerda" (PERISSINOTTO; MIRÍADE, 2009, p. 312), indistinta a posição no espectro ideológico estão os políticos profissionais. É justamente nesses padróes sociais característicos dos partidos políticos brasileiros que Rodrigues $(2002,2009)$ demonstra que as principais mudanças no perfil da Câmara dos Deputados entre o fim dos anos 1990 e o início dos anos 2000 decorre de um avanço dos partidos de esquerda na Câmara Baixa do Parlamento, precisamente o período (19992006) aqui em estudo sobre as bancadas do Senado Federal.

Tudo isso torna ainda mais pertinente avançar o estudo, ao passo que Lemos e Ranincheski (2008) já detectaram que os Senadores da década de 1990 eram mais experimentados politicamente que seus colegas da Câmara dos Deputados, espera-se apontar a natureza dessa expertise e as principais características das bancadas que compuseram o período. A Casa da Federação por si já tem um "tom” de elite, sendo o único ente Legislativo com eleição majoritária, tradicionalmente disputado por Governadores, Deputados de longevas carreiras e até mesmo Presidentes da República: "A elite política se encontra no Senado Federal" (CENTENO, 2018, p. 57). 
Tabela I - Número de parlamentares (por ano, entre 1999 e 2006) nas bancadas das $5 \mathrm{I}^{\mathrm{a}}$ e $52^{\mathrm{a}}$ legislaturas ${ }^{6}$

\begin{tabular}{lcccccccc}
\hline Part./Ano & $\mathbf{1 9 9 9}$ & $\mathbf{2 0 0 0}$ & $\mathbf{2 0 0 1}$ & $\mathbf{2 0 0 2}$ & $\mathbf{2 0 0 3}$ & $\mathbf{2 0 0 4}$ & $\mathbf{2 0 0 5}$ & $\mathbf{2 0 0 6}$ \\
\hline DEM & 19 & 21 & 21 & 18 & 18 & 17 & 17 & 16 \\
PCdoB & 0 & 0 & 0 & 0 & 0 & 0 & 0 & 1 \\
PDT & 2 & 3 & 3 & 5 & 5 & 5 & 4 & 4 \\
PR & 0 & 0 & 0 & 1 & 3 & 3 & 3 & 3 \\
PMDB & 27 & 26 & 26 & 25 & 20 & 23 & 23 & 20 \\
PRB & 0 & 0 & 0 & 0 & 0 & 0 & 0 & 1 \\
PP & 4 & 2 & 2 & 3 & 0 & 0 & 0 & 0 \\
PPS & 1 & 3 & 3 & 3 & 3 & 2 & 1 & 0 \\
PSB & 3 & 3 & 3 & 3 & 3 & 3 & 2 & 3 \\
PSDB & 16 & 14 & 14 & 12 & 11 & 11 & 13 & 15 \\
PSOL & 0 & 0 & 0 & 0 & 0 & 0 & 1 & 1 \\
PT & 8 & 7 & 7 & 7 & 14 & 13 & 13 & 12 \\
PTB & 1 & 1 & 1 & 4 & 4 & 3 & 3 & 4 \\
S/P* & 0 & 1 & 1 & 0 & 0 & 1 & 1 & 1 \\
\hline & & & Fonte: Senado Federal (20/7). & & &
\end{tabular}

Como se pode observar na Tabela 1, que capta movimentaçóes e alteraçóes entre as bancadas, PMDB, DEM, PSDB e PT foram os maiores partidos no Senado Federal durante os anos de 1999 e 2006; especialmente o PMDB, que nunca teve menos de $25 \%$ da composição da Casa. Entre as $51^{\mathrm{a}}$ e $52^{\mathrm{a}}$ Legislaturas, o DEM (antigo PFL), ainda obtinha números robustos nas urnas na disputa pela representação das Unidades da Federação, em patamares que se aproximavam do PMDB. As bancadas tucanas, a cada Sessão Legislativa (cada ano de uma Legislatura, que dura quatro anos), decresceram durante o segundo período do governo FHC; mas, ascenderam nos anos em que o partido foi oposição ao governo Lula. Ao PT coube o movimento surpreendente de dobrar sua bancada entre 2002

6 Os partidos PCdoB, PRB e PSOL receberam Senadores em meio de mandato. 
e 2003 (período que marca a eleição de Lula, concomitante às eleiçôes legislativas e à chegada do partido ao Palácio do Planalto), visto que o PT historicamente obtém números magros na disputa pelo Senado.

Durante esse período, não houve tamanha fragmentação partidária como a que se observou a partir de 2010; porém, receberam representantes os partidos então recém-criados PSOL, PR e PRB, enquanto o PCdoB ganhou um Senador. Partidos médios como o PDT e o PSB se mantiveram estáveis; já o crescimento do PPS no início dos anos 2000 foi reduzido a nenhum político representando o partido, havendo um aumento considerável do PTB na Casa e o periódico (posteriormente revertido) desaparecimento do PP. Para efeitos de análise, esses novos partidos e as movimentações dentro das bancadas não serão avaliados; observar-se-á apenas o quadro partidário no início de cada legislatura (1999 e 2003) em estudo.

A fim de dinamizar a análise, as profissóes e as diplomaçóes dos Senadores foram divididas por áreas na Tabela 2, não havendo prejuízo no detalhar das informações, pois se pretende esmiuçar esses dados ao longo dos próximos parágrafos. Todavia, reforça-se que essas classificaçôes evitam de a tabela ter mençôes minuciosas em casos nos quais profissôes e diplomas figuraram em apenas uma biografia. Tão importante quanto isso, é aferir que há um claro descompasso nas áreas de profissão e diplomação: enquanto diplomas em Direito, assim como nas "Engenharias", superaram os percentuais de profissionais desses segmentos, as áreas da "Comunicação" e "Economia e Negócios" tiveram patamares maiores de profissionais no ramo (decorrente, respectivamente, dos casos de jornalistas, radialistas e apresentadores sem diploma em Jornalismo/ Comunicação Social e dado o alto volume de empresários - profissão com indistinção de formação prévia). A isso, soma-se a particularidade que "muitos políticos não exercem profissão na área de diplomação" (MADEIRA; CENTENO, 2018). 
Tabela 2 - Diplomações e profissões dos senadores (1999-2006) por área de classificação

\begin{tabular}{|c|c|c|c|c|c|}
\hline Área da profissão & $\mathbf{N}^{\circ}$ & $\%$ & Área do diploma & $\mathbf{N}^{\circ}$ & $\%$ \\
\hline Jurídica & 30 & 22,2 & Jurídica & 43 & 31,9 \\
\hline Economia e Negócios & 28 & 20,7 & Economia e Negócios & 17 & 12,6 \\
\hline Engenharias & 15 & 11,1 & Engenharias & 17 & 12,6 \\
\hline Ensino & 13 & 9,6 & Saúde & 11 & 8,1 \\
\hline Saúde & 13 & 9,6 & Ensino & 6 & 4,4 \\
\hline Comunicação & 8 & 5,9 & Ensino Médio & 6 & 4,4 \\
\hline Agricultura, pecuária e afins & 6 & 4,4 & Técnica & 5 & 3,7 \\
\hline Diplomacia e Serviço Público & 5 & 3,7 & Ciências Naturais & 4 & 3 \\
\hline Outros & 5 & 3,7 & Ciências Sociais & 4 & 3 \\
\hline Ciências Naturais & 3 & 2,2 & Agricultura, pecuária e afins & 3 & 2,2 \\
\hline Ciências Sociais & 2 & 1,5 & Comunicação & 3 & 2,2 \\
\hline Técnica & 1 & 0,7 & Outros & 3 & 2,2 \\
\hline TOTAL & 135 & 100 & TOTAL & 135 & 100 \\
\hline
\end{tabular}

Fonte: Senado Federal (2017).

No Senado, historicamente predominaram os bacharéis (LEMOS; RANINCHESKI, 2008; CORADINI, 2007; NEIVA; IZUMI, 2014; CENTENO, 2018), não sendo diferente durante as 51 a e 52a Legislaturas. Apenas 24 dos 135 políticos que passaram pela Casa da Federação ao longo dos anos em estudo tinham diplomas de ensino médio/técnico ou formação imprecisa por falta de dados. De maneira prévia, essas informações vão ao encontro das escritas de autores já citados - Rodrigues (2002, 2009) e Gaxie (2012) - bem como da literatura de Bourdieu (2002), mostrando o diferencial do capital cultural dentre setores da elite política nacional.

A tradição foi reforçada também pela diplomação mais recorrente entre os Senadores do intervalo: o bacharelado em Direito se fez presente em 43 biografias, número maior que a soma dos diplomados nas áreas de Economia e Negócios e nas "Engenharias”, que agregam vários diplomas. Mesmo que cerca de 1/3 não tenha exercido profissão na área, ainda assim os profissionais do ramo jurídico foram maioria na Casa. O histórico 
do diploma em Ciências Jurídicas e dos profissionais do meio atravessam gerações no Senado (Codato et al., 2016), bem como se reforçam para o período, considerando que cinco dos seis Presidentes do Senado durante o ínterim eram bacharéis em Direito.

Esse predomínio também "atravessa as fronteiras" do espectro ideológico (Anexo I), mais da metade dos democratas (15 de 28) e 40\% dos peemedebistas tinham formação na área. Nas bancadas dos pequenos partidos de esquerda (PDT, PSB e PPS), onde cada legenda teve cinco Senadores entre 1999 e 2006, havia dois formados em Direito em cada partido, dando a esses, análogo percentual de formados em Ciências Jurídicas do PMDB. O mesmo náo foi detectado entre os pequenos partidos de direita, tampouco no PSDB - única legenda, entre as que aqui estão sendo estudadas, na mesma posição ideológica do PMDB (entre os tucanos, apenas quatro dos 23 políticos do partido tinham tal graduação). De todos os partidos no Senado, apenas o PR não teve pelo menos um graduado em Direito.

Não diferente foi a incidência de diplomas nas divisôes das "Engenharias". Com exceção do PPS e do PP, em todos os partidos havia pelo menos um graduado em um dos ramos da área. Se observados isoladamente (Civil, Mecânica etc.), esses produzem pequenos números dispersos; porém, quando agregados pela ciência, em partidos como o PSB, as "Engenharias" superam até mesmo o número de formados no ramo Jurídico, enquanto o número de tucanos formados nesse campo é análogo aos formados em Direito.

Cabe destacar outro diploma "universal" entre os partidos durante as duas legislaturas: Medicina. Apenas alguns partidos com pequenas bancadas como PSB, PP e PR não tinham políticos com essa formação, diferentemente do PTB, chegando a dois dos cinco Senadores da agremiação com bacharelado na área. Apesar de espraiada pelas mais distintas legendas, esse diploma não alcançou números volumosos nos mandatos dos grandes partidos, apenas dois democratas e outros dois petistas eram graduados em Medicina; nos de centro (PMDB e PSDB), havia apenas um em cada. Entre os quatro grandes do Senado - PMDB, DEM, PSDB e PT, cabe destacar a diplomação em Economia/Ciências Econômicas, sendo três po- 
líticos tucanos, dois petistas, e dois divididos entre PMDB e DEM (o PPS também teve um bacharel em Economia).

Observa-se de tal forma a universalização de diplomas tradicionais em partidos dos três segmentos ideológicos, também em legendas das mais diversas magnitudes, desde nanicos até os partidos que dominaram a Casa da Federação ao longo dos anos em estudo. Há casos em que formaçôes se revelaram apenas em alguns partidos, mas sempre com apenas um político entre mais de uma centena em estudo: por exemplo, um formado em Geografia no PT, outra graduada em Arquitetura, no mesmo partido, um bacharel em Educação Física no PP e um em Teologia no PR. É imprescindível pontuar que essas comparaçóes tratam de um pequeno universo de 135 políticos, não representando tendência, tampouco sendo plausível carimbar essas detecçóes como características das legendas.

Formaçóes nas áreas de Administração/Administração de Empresas e Agronomia somente se fizeram presentes nos partidos de centro e direita, ao passo que diplomaçôes em Jornalismo/Comunicação apenas foram detectadas em biografias dos dois partidos de centro, sendo os únicos casos em termos educacionais no social background dos políticos com assento na Casa da Federação durante o período em estudo em que há uma profunda diferenciaçáo entre os partidos de acordo com seu posicionamento na escala esquerda-centro-direita. Até mesmo em áreas humanas, como na História, havia uma petista e um tucano com formação na área; na Pedagogia, havia um caso no PPS e outro no DEM; Geologia, um petista e um democrata; Ciências Sociais/Sociologia, um no PMDB e equivalente no DEM; por fim, nas Letras, uma petista e um peemedebista.

Assim, é relevante que - para termos de análise do período e tão somente do período -, com pequenas exceções, os partidos no Senado Federal pouco se distinguiram em termos de recrutamento, no que se refere aos diplomas dos políticos que passaram pela Câmara Alta. Isso porque, para além do predomínio do quarteto PMDB, DEM, PSDB e PT, que fez com que os demais partidos ficassem reduzidos, houve nove casos imprecisos (onde não se pode constatar com precisão a diplomação do Senador) e três biografias que possuíam diversos diplomas em diferentes áreas. Cabe, então, averiguar se o mesmo se repete no social background dos Senadores 
quando observada a profissão prévia à carreira política; afinal, como recentemente afirmado, há áreas nas quais os índices de diplomação se distinguem fortemente do patamar de profissionais.

As profissóes entre os políticos de partidos de esquerda durante o período em análise trazem algumas curiosidades: o PT, maior partido nesse espectro ideológico, apresentava um grande conjunto de distintas formações entre seus integrantes, tendo mais de $20 \%$ de seus políticos como antigos professores universitários; somados a esses, dois professores de ensino básico deram a seis entre os 19 Senadores da legenda o histórico profissional ligado ao Ensino. Já nos pequenos partidos de esquerda, ao passo que os pedetistas e os Senadores do PPS formados em Direito foram fidedignos à área e atuaram como advogados, no PSB havia uma profissão diferente para cada um dos cinco Senadores que passaram pelo partido entre 1999 e 2006. Todos os formados em Medicina que eram dos partidos de esquerda declararam ter exercido a profissão; no que se refere ao quesito profissional no social background de Senadores dos partidos de esquerda, não houve o descompasso encontrado no todo da Casa quanto ao diferencial de atuação na área de formação.

O mesmo não ocorreu nos partidos de centro: inicialmente, porque dos $40 \%$ de peemedebistas formados na área Jurídica, pouco mais de $1 / 3$ atuou na área; segundo, o contingente de empresários nos partidos que representam esse espectro ideológico foi maior que na soma desses profissionais nos partidos de direita (não houve nenhum empresário em partidos de esquerda). Existiam seis empresários no PMDB e quatro no tucanato nas $51^{\mathrm{a}}$ e $52^{\mathrm{a}}$ Legislaturas. E estas foram as únicas legendas com graduados na área da Comunicação. Esses partidos abrigaram todos os profissionais jornalistas (no PTB, pequeno partido de direita, havia um radialista). Por fim, cabe mencionar que, entre os cinco políticos que se declararam pecuaristas/agropecuaristas, quase todos estavam no PSDB, com exceção de um no PP.

Como já tangenciado, empresários também foram uma característica profissional dos Senadores dos partidos de direita; porém, é fundamental colocar que em todos os pequenos partidos desse campo ideológico (PP, PR e PTB), essa profissão foi de dois dos cinco Senadores que cada partido ti- 
nha, mesmo número do DEM (que teve 28 Senadores no intervalo). Nesse último partido, havia nove advogados, um promotor e um delegado; essa legenda apresentou múltiplas características em termos de recrutamento profissional, havendo no mínimo treze profissóes distintas declaradas (dois Senadores não tinham declaração profissional em suas biografias). Ainda nas pequenas agremiaçóes de direita, destacam-se dois engenheiros no PR e dois médicos no PTB; apesar do pequeno número de políticos nesses partidos, em termos de recrutamento as características foram concisas.

Essas duas profissões já haviam se mostrado universalizadas em termos de diplomaçôes nos partidos dos mais distintos posicionamentos na escala esquerda-centro-direita (o ramo da "Saúde", como apresentado na Tabela 2 , é um campo onde os políticos com mandato no período em estudo mais se mantiveram na profissão da linha de formação). Todavia, há exceçôes: enquanto o PSB teve três de seus cinco Senadores com diploma na área das "Engenharias", apenas um declarou ter atuado profissionalmente; no PSDB, os engenheiros empataram com os empresários e formaram quatro dos representantes da legenda; no DEM, igualaram-se ao número de médicos (três).

Essa última profissão, ecumênica entre as legendas em termos de formação educacional, não teve profissionais apenas no PR e no PSB. O diploma em Ciências Econômicas/Economia, que se destacou nos quatro grandes partidos do Senado (PMDB, DEM, PSDB e PT), somente teve profissionais economistas nessas legendas. Contudo, enquanto os diplomados somaram 11, os que atuaram previamente ao mandato no Senado eram apenas sete, um no DEM e os demais divididos equitativamente nas outras três legendas. Sintetiza-se que, no social background dos Senadores, as diferenças entre os partidos políticos se acentuaram quanto às profissôes. Além do fato, acima pontuado, de que muitos políticos não chegam a atuar no seu ramo de formação, a função de empresário (ocupação importante nos partidos de centro e direita) não requer instrução educacional específica e pode ser desempenhada concomitante ao mandato.

\section{Carreiras prévias aos mandatos senatoriais}

Tendo trabalhado com os dados do social background dos 135 Senadores que tiveram assento nas duas legislaturas em estudo, passa-se 
para a parte final da análise que permeia a experiência política desses Senadores, analisando a construção de suas carreiras e as principais características dessas. Adota-se análoga divisão e classificação dos cargos outrora utilizada na dissertação a qual esse artigo está vinculado: "Eletivos" (quando o Senador, apenas exerceu cargos para os quais foi eleito), "Nomeativos" (para os casos em que o Senador apenas exerceu cargos para os quais foi nomeado), "Ambos" (experiência ou no Executivo, ou no Legislativo, e em cargos por indicação), "Nenhum" (sem carreira institucional e burocrática) e "Todos" (para quando o Senador exerceu mandatos no Executivo, no Legislativo e em postos de nomeação). Não havendo menção e/ou diante da falta de informação nas biografias, esses foram taxados como "Impreciso".

De saída, percebe-se a profunda diferença que o quesito gênero traz para as carreiras políticas. O pequeno número de mulheres no Senado durante o período foi de uma bancada feminina com carreira construída sobretudo por mandatos eletivos. Não que entre os homens tenha predominado a carreira por cargos de nomeação; do pequeno número de Senadores com essa característica, somente havia uma Senadora entre os 13 do grupo. Além disso, 60 políticos dos 135 em estudo tiveram carreiras solidificadas por mandatos obtidos somente nas urnas. Outros 19 tiveram experiência ou no Executivo, ou no Legislativo, e em cargos por indicação.

Tabela 3 - Experiência dos senadores em cargos eletivos e nomeativos, por gênero e situação (titular x suplente) - 1999-2006

\begin{tabular}{lcccccc}
\hline & Gênero & \multicolumn{2}{c}{ Situação } & \multicolumn{2}{c}{ Total } \\
\hline Cargo (s) & F & M & Suplente & Titular & $\mathbf{N}^{\circ}$ & $\%$ \\
\hline Eletivos & 9 & 51 & 6 & 54 & 60 & 44,4 \\
Nomeativos & 1 & 13 & 4 & 10 & 14 & 10,4 \\
Ambos & 1 & 18 & 0 & 19 & 19 & 14,1 \\
Todos & 0 & 21 & 0 & 21 & 21 & 15,6 \\
Nenhum & 2 & 13 & 7 & 8 & 15 & 11,1 \\
Impreciso & 0 & 6 & 5 & 1 & 6 & 4,4 \\
\hline TOTAL & 13 & 122 & 22 & 113 & 135 & 100 \\
\hline
\end{tabular}

Fonte: Senado Federal (20/7) e CPDOC (20/7). 
No que se soma uma maioria absoluta de políticos com pelo menos uma vitória nas urnas em suas carreiras antes de chegarem ao Senado Federal, aprofundam-se as diferenças de gênero quando é analisado o contingente de políticos cujas carreiras foram rotuladas por histórico de mandatos no Executivo, no Legislativo e em postos de nomeação (todos): apenas 21 (nenhum suplente) alcançaram tamanha experiência; porém, nenhuma Senadora.

As distinções dos partidos, que eram mais profícuas na profissão pregressa à carreira política, se acentuam quando estudada e detalhada a construção da experiência no campo político profissional de acordo com a divisão partidária no Senado. Era do $\mathrm{PMDB}$ um terço dos políticos que tinham histórico de mandatos no Executivo, no Legislativo e em postos de nomeação; era desse mesmo partido o único político que na época somava dez mandatos antes do que então exercia no Senado (José Maranhão - PMDB/PB). Outro um terço de políticos com carreiras marcadas pela passagem em "Todos" os aspectos institucionais do poder, estava no DEM; metade dos que tinham oito mandatos eletivos na bagagem eram democratas, os demais, peemedebistas.

Mesmo que compondo o grande quarteto de partidos no Senado, o PT não integrou essa máxima de experimentação, junto de pequenos partidos como o PP e o PTB. Todas as demais legendas tinham pelo menos um político com esse grau de experimento. Inclusive, foram os petistas que lideraram o número de Senadores que não tinham nenhum cargo político prévio ao mandato, cinco de um total de 15 . Ainda assim, metade da bancada do partido era composta de políticos com "curriculum" marcado por mandatos eletivos. Petistas, tucanos e democratas somaram o maior conjunto de Senadores que somente exerceram cargos de nomeação antes de chegarem à Casa da Federaçáo, onde o DEM teve cinco dos 14, junto de dois pedetistas, um pessebista, três tucanos e equivalentes petistas.

A menor expertise petista não se encontrou nos demais partidos de esquerda, pois no PPS, no PSB e no PDT nenhum político deixou de ter pelo menos um posto eletivo ou nomeativo prévio ao mandato de Senador. O principal adversário do PT fez uma bancada mais próxima dos outros dois grandes partidos da Casa, com tucanos de histórico de mandatos ex- 
clusivamente eletivos (oito de 23 políticos do PSDB), onde somente quatro partidários não dispunham de experiência prévia comprovada.

Pode-se afirmar que o Senado Federal, entre os anos de 1999 e 2006, foi composto sobretudo de políticos versados. Essa realidade não foi diferente entre os pequenos partidos de direita. Ainda que no PR houve dois de seus cinco partidários totalmente inexperientes, no PTB todos os Senadores da legenda tinham pelo menos um cargo eletivo anterior ao mandato em exercício, mesmo caso de três políticos do PP.

Tabela 4 - Experiência (absoluta e relativa) dos senadores em cargos eletivos e nomeativos, de acordo com o posicionamento do partido na escala ideológica - 1999-2006

\begin{tabular}{lccccccc}
\hline \multicolumn{7}{c}{ Classificação ideológica } \\
\hline Cargo (s) & Esquerda & $\%$ & Centro & $\%$ & Direita & $\%$ & Total \\
\hline Ambos & 2 & 5,88 & 9 & 15,52 & 9 & 20,93 & 20 \\
Eletivos & 17 & 50,00 & 29 & 50,00 & 15 & 34,88 & 61 \\
Impreciso & 1 & 2,94 & 2 & 3,45 & 3 & 6,98 & 6 \\
Nenhum & 5 & 14,71 & 5 & 8,62 & 4 & 9,30 & 14 \\
Nomeativos & 6 & 17,65 & 3 & 5,17 & 4 & 9,30 & 13 \\
Todos & 3 & 8,82 & 10 & 17,24 & 8 & 18,60 & 21 \\
\hline TOTAL & 34 & 100 & 58 & 100 & 43 & 100 & 135 \\
\hline
\end{tabular}

Fontes: Senado Federal (2017) e CPDOC (2017).

Deveras, resguardadas as características pontuais (como o caso dos profissionais do ensino no PT e os políticos inexperientes no mesmo partido), pode-se pensar o Senado durante os anos de 1999 e 2006 como Casa Legislativa de políticos com social background destacado, cujas titulaçóes e profissões são comuns entre as legendas, fator corroborado pela experimentaçáo política também regular e frequente entre os partidos, mais acentuada nos partidos de centro e direita, cujos políticos tenderam a passar pelas diversas naturezas de cargos políticos. Todavia, há diferenças nessa formação de expertise política pelos Senadores no que tange à magnitude e à projeção dos cargos que exerceram previamente. 
Indiscutivelmente, ao longo do intervalo em estudo, houve predomínio de carreiras de natureza eletiva, indistinto o partido, indiferente o posicionamento no espectro ideológico. Quando esmiuçado pelo poder e pela esfera, surgem pontos nevrálgicos para o entendimento do Senado Federal como a casa da elite política brasileira. Ao todo, 39 dos 135 Senadores tinham exercido o cargo de Governador, enquanto 59 foram Deputados Federais antes de chegarem à Câmara Alta. Durante essas duas legislaturas, até mesmo o ex-Presidente José Sarney (PMDB/AP) e o ex-Vice-Presidente Marco Maciel (DEM/PE) passaram pela Casa da Federação.

Vê-se, de antemão, que boa parte dos Senadores do período exerceu os dois postos eletivos de maior projeção abaixo da Presidência da República e do próprio mandato senatorial. Desses políticos, 34 também foram Prefeitos ao longo de suas carreiras: mais da metade (18) deles nos partidos de centro, dez nos partidos de direita e apenas seis nos partidos de esquerda. No PT, nenhum de seus Senadores foi eleito Prefeito antes de chegar ao lado esquerdo do Palácio Nereu Ramos; ao contrário do PSB, pois três Senadores deste partido anteriormente já tinham chefiado algum Paço Municipal. Ademais, 13 peemedebistas e cinco tucanos tinham tal feito em suas biografias, e também em todos os partidos de direita havia pelo menos um ex-Prefeito em suas bancadas.

Subindo na esfera do Poder Executivo, ainda que aumente o número de políticos com passagem pelo cargo de Governador em relação ao de Prefeito, diminui o número de partidos com mandatários de semelhante característica. Com exceção do DEM, nenhum partido de direita tinha algum político que tenha chefiado Palácio Estadual (11 dos 28 democratas administraram seus estados). Essa não é uma realidade muito diferente dos partidos de esquerda: até mesmo o PDT e o PPS (que, diferentemente do PT, tinham ex-Prefeitos entre seus representantes no Senado) náo elegeram Senadores para governos estaduais em suas trajetórias. Um entre os 19 petistas fez esse contraponto na bancada majoritariamente desprovida de histórico executivo, enquanto o PSB reforçou sua experiência executiva com dois ex-Governadores. Já nos partidos de centro, cerca de dois em cada cinco Senadores exerceram o cargo antes de chegarem ao Senado, sobretudo no PMDB; afinal, nessa legenda, mais da metade dos mandatários havia sido Governador previamente. 
Quando observada a experiência política no Legislativo dos integrantes das bancadas que compuseram as duas legislaturas em análise, quanto maior a projeção do cargo legislativo abaixo do cargo de Senador, maior a incidência desse nas biografias estudadas. Ao todo, 26 dos Senadores das $51^{\mathrm{a}}$ e $52^{\mathrm{a}}$ Legislaturas haviam sido Vereadores em suas carreiras; esse número quase dobra e chega a 51 ex-Deputados Estaduais, e sobe para os já citados 59 ex-Deputados Federais.

De todos os partidos, somente o PDT e o PTB não tinham Senadores que passaram pela Câmara dos Deputados. Aqui, até mesmo o partido com o maior volume de políticos inexperientes, o PT, tinha cinco de seus 19 partidários com passagem pelo lado direito do Congresso Nacional; tanto DEM como PMDB tinham quase metade de suas bancadas com políticos que anteriormente foram eleitos Deputados Federais. Poucos Senadores haviam exercido o próprio posto anteriormente - 22 dos 135 políticos em estudo: seis democratas e 11 peemedebistas tinham pelo menos um mandato anterior ao exercido durante o ínterim.

Enquanto apenas três Senadores passaram por secretarias municipais, 35 foram indicados para secretarias estaduais ao longo de suas carreiras; porém, apenas dez Senadores foram Ministros de Estado antes de tomarem assento no Senado da República. Os postos de secretários em governos nas unidades federativas estiveram presentes nas biografias de pelo menos um Senador em cada partido que compôs as duas legislaturas sob análise. Já o cargo de Ministro foi exercido apenas por um petista, seis democratas e três peemedebistas.

Ressalta-se que, por mais importantes que os postos nomeativos sejam para as carreiras políticas, em muitas ocasióes servindo de trampolim para campanhas eleitorais, esses são pouco valorizados nos relatos das carreiras dos Senadores. Além disso, é possível que um político exerça um cargo de nomeação enquanto está incumbido em um mandato no legislativo. Esses, entre outros fatores, retiram o protagonismo dos cargos de nomeação e deixam biografias oficiais e extraoficiais com ausência de registros importantes para a pesquisa de carreiras políticas.

Observa-se, portanto, que os Senadores dos partidos de centro e direita tinham carreiras mais largas, eram mais versados na política em relação 
aos seus homólogos dos partidos de esquerda, sobretudo pelos padrões do maior partido desse espectro ideológico - o PT, onde prevaleceu a menor experiência prévia ao mandato na Casa da Federação. $\mathrm{O}$ predomínio dos partidos de centro (principalmente o PMDB) e, sobretudo, do DEM na direita justifica os padrôes encontrados; entretanto, é inevitável pontuar que, mesmo em pequenas legendas, muitas dessas constataçóes se repetiam, assim como a formação educacional semelhante dos membros de pequenos partidos de esquerda em relação à titulação escolar de Senadores dos partidos de centro e direita.

\section{Considerações finais}

Inicialmente visando a comparar o social background e a formação de carreiras dos políticos de acordo com o posicionamento dos partidos no espectro ideológico, observou-se, no transcorrer da análise, uma relativização (ao menos nas duas legislaturas em estudo) da colocação de Perissinotto e Miríade (2009) em seu estudo sobre a Câmara dos Deputados, quanto às posiçôes sociais mais elevadas nos partidos de centro e direita, e de médias a baixas nas legendas de esquerda.

Como já mencionado, durante o período, os partidos no Senado se distinguiram mais pela profissão pregressa à carreira política. Os petistas foram marcados por carreiras ligadas ao ensino, ao passo que, nos partidos de centro e direita, havia um grande número de empresários. Todavia, simultaneamente, as legendas de direita tinham uma grande teia de profissóes nos mais distintos ramos. $\mathrm{O}$ que mais pesou nessa relativização foi o contingente de médicos e advogados nos pequenos partidos de esquerda. Soma-se a isso o fato que no Senado Federal, em termos de formação e titulação escolar, houve uma tríade de diplomaçóes que imperou nas mais diversas legendas: Direito, "Engenharias" e Medicina. Os quatro grandes partidos no Senado - PMDB, DEM, PSDB e PT - também se assemelhavam por terem quase a totalidade dos graduados em Ciências Econômicas/Economia.

Novamente trazendo a leitura de Perissinotto e Miríade (2009), indiferente o espectro ideológico, os políticos profissionais se sobressaem no Congresso Nacional. No estudo que se encerra, há constataçóes importantes para esse entendimento e para futuras empreitadas que visem a 
aprofundar os conhecimentos sobre o Senado Federal: o PMDB e o DEM agregaram a maior parte dos políticos aqui descritos como de grau maior de experimentação política (mandatos no Executivo, Legislativo e cargos de nomeação), bem como de políticos que mais acumularam mandatos antes de chegarem no Senado. Entre os Senadores do período, aqueles que, em suas carreiras, tinham cargos eletivos no Executivo eram majoritariamente de partidos de centro e direita.

Nos pequenos partidos de esquerda, averiguou-se que, apesar da maior experiência em relação ao maior partido desse espectro ideológico - o PT, esses continuavam parcialmente menos experientes que os políticos das legendas de centro e direita. Uma possibilidade para tal conjuntura jaz na perseguiçáo e na ilegalidade que muitos políticos foram jogados durante o período ditatorial. Assim, este estudo incita trabalhos que vão além do estudo de carreiras, aprofundando as leituras das biografias para melhor compreender o quadro aqui apresentado: de uma assembleia da elite política brasileira.

Como pontuado no início do presente trabalho, pelo Senado Federal passam muitos dos políticos brasileiros mais experientes, seja em termos de longevidade política, seja na envergadura do cargo que ocuparam. Não por acaso, no detalhar da formação das carreiras dos políticos em estudo, um ex-Presidente e diversos ex-Governadores compuseram as duas legislaturas sob análise. Ressalva-se que, ainda em maior número, a ampla experiência legislativa dos 135 Senadores do período precisa ser observada sem sobressair diante dos chefes de executivo estadual.

Os 39 ex-Governadores representam políticos que disputaram eleições majoritárias vencidas por maioria absoluta de votos, método diferente da própria votação para Senador; simultaneamente, os Deputados Federais são eleitos por regras profundamente distintas e tomam posse em um conjunto superior a cinco centenas, frente aos 27 que assumem os palácios estaduais. Assim, reforça-se a preeminência da elite política, mostrando o Senado como caminho natural dos políticos que alcançaram o ápice de suas carreiras em âmbito estadual ou mesmo daqueles que foram Chefes da Nação e do Estado brasileiro. Posteriormente à chegada de José Sarney em 1990, Fernando Collor de Mello e Itamar Franco também foram eleitos Senadores. É a Câmara Alta do Parlamento do Brasil o ponto de encontro da alta-roda da política nacional. 


\section{Referências}

ARAÚJO, Paulo Magalhães. Recrutamento parlamentar para o Senado e o perfil dos senadores brasileiros, 1989-2006. Revista Política Hoje, Recife, v. 20, n. 2, p. 550-580, 2011.

BOURDIEU, Pierre. O poder simbólico. Rio de Janeiro: Bertrand Brasil, 2002.

CENTENO, Alison Ribeiro. Os maestros da elite: carreiras e trajetórias dos líderes no Senado Federal entre 1999 e 2006. 2018. 174f. Dissertação (Mestrado em Ciências Sociais) - Escola de Humanidades, Pontifícia Universidade Católica do Rio Grande do Sul, Porto Alegre, 2018. Disponível em: http://tede2.pucrs.br/tede2/handle/tede/8046.

COSTA, Luiz Domingos; CODATO, Adriano. Profissionalização ou popularização da classe política brasileira? Um perfil dos senadores da República. Textos para discussáo, Curitiba, n. 2, p. 1-28, abr. 2012.

COSTA, Luiz Domingos; CODATO, Adriano; MASSIMO, Lucas; HEINZ, Flavio. Regime político e recrutamento parlamentar: um retrato coletivo dos senadores brasileiros antes e depois da ditadura. Revista de Sociologia e Política, Curitiba, v. 24, n. 60, p. 47-68, dez. 2016.

CORADINI, Odaci Luiz. Engajamento associativo-sindical e recrutamento de elites políticas. Revista de Sociologia e Política, Curitiba, n. 28, p. 181-203, jun. 2007.

CORADINI, Odaci Luiz. Categorias sócio-profissionais, titulaçáo escolar e disputas eleitorais. Revista de Sociologia e Política, Curitiba, v. 20, n. 41, p. 109-122, fev. 2012.

GAXIE, Daniel. As lógicas do recrutamento político. Rev. Bras. Ciênc. Polít., Brasília, n. 8, p. 165-208, ago. 2012.

LEMOS, Leany Barreiro; RANINCHESKI, Sônia. Carreiras políticas no Senado brasileiro: um estudo das composições do Plenário e da Comissão de Constituição, Justiça e Cidadania na década de 90. In: LEMOS, Leany Barreiro (org.). O Senado Federal brasileiro no pós-constituinte. Brasília: UniLegis; Senado Federal, 2008. p. 87-120.

MADEIRA, Rafael Machado, CENTENO, Alison Ribeiro. A “dança das cadeiras” está circunscrita à Câmara dos Deputados? Uma análise da evolução da fragmentação partidária e da origem socio-ocupacional dos eleitos ao Senado Federal, aos governos dos estados e às suas respectivas capitais. In: $11^{\circ}$ Encontro da ABCP, 2018. Disponível em: https://cienciapolitica.org. $\mathrm{br} /$ system/files/documentos/eventos/2019/05/danca-das-cadeiras-esta-circunscrita-camara-dosdeputados.pdf

MIGUEL, Luís Felipe. Capital político e carreira eleitoral: algumas variáveis na eleição para o Congresso brasileiro. Rev. Sociol. Polit., Curitiba, n. 20, p. 115-134, jun. 2003.

MIGUEL, Luís Felipe; MARQUES, Danusa; MACHADO, Carlos. Capital Familiar e Carreira Política no Brasil: Gênero, Partido e Regiáo nas Trajetórias para a Câmara dos Deputados. Dados, Rio de Janeiro, v. 58, n. 3, p. 721-747, 2015. 
NEIVA, Pedro. Coesão e disciplina partidária no Senado Federal. Dados, Rio de Janeiro, v. 54, n. 1, p. 289-318, 2011.

NEIVA, Pedro; IZUMI, Maurício. Perfil profissional e distribuição regional dos senadores brasileiros em dois séculos de história. Rev. Bras. Ciências Sociais, São Paulo, v. 29, n. 84, p. 165188, fev. 2014.

PERISSINOTTO, Renato Monseff; MIRIADE, Angel. Caminhos para o parlamento: candidatos e eleitos nas eleiçóes para deputado federal em 2006. Dados, Rio de Janeiro, v. 52, n. 2, p. 301-333, jun. 2009.

PERISSINOTTO, Renato Monseff; VEIGA, Luciana Fernandes. Profissionalização política, processo seletivo e recursos partidários: uma análise da percepção dos candidatos do PT, PMDB, PSDB e DEM nas eleições para Deputado Federal de 2010. Opiniáo Pública, Campinas, v. 20, n. 1, p. 49-66, abr. 2014

POWER, Timothy J.; ZUCCO JR., Cesar. Estimating ideology of Brazilian Legislative Parties, 1990-2005: A reserach communication. Latin American Research Review, Baltimore, v. 44, n. 1, p. 218-246, 2009.

RODRIGUES, Leôncio Martins. Partidos, ideologia e composição social. Revista brasileira de Ciências Sociais, São Paulo, v. 17, n. 48, p. 31-47, fev. 2002.

RODRIGUES, Leôncio Martins. Mudanças na classe política brasileira. Biblioteca Virtual de Ciências Humanas do Centro Edelstein de Pesquisas Sociais, Rio de Janeiro, 2009. Disponível em: http://www.bvce.org.br/LivrosBrasileirosDetalhes.asp?IdRegistro=114. Acesso em: 29 set. 2018.

Recebido: 28/11/2019

Aceito: 29/04/2020 


\section{Route to the Federal Senate: Brazilian Senator's political careers and social background in the 5 Int legislatures}

\section{Abstract}

Analyzing the Brazilian Federal Senate between 1999 and 2006 the main objective is to present the characteristics of recruitment of the Senators who had a seat in the Upper House according to parties' position in the political spectrum. Exploring a database consisting of information such as academic degree, profession before the political career and positions previously held by the 135 politicians with mandates during the interim, the Federal Senate was composed mainly of politicians with bachelor's degrees, who were reasonably distinct in their previous professions and with a strong contrast in the formation of their political careers - high level of experience for center and right parties' politicians and less experience of Senators from the left.

Keywords: Brazilian Senate. Political careers. Social background. 


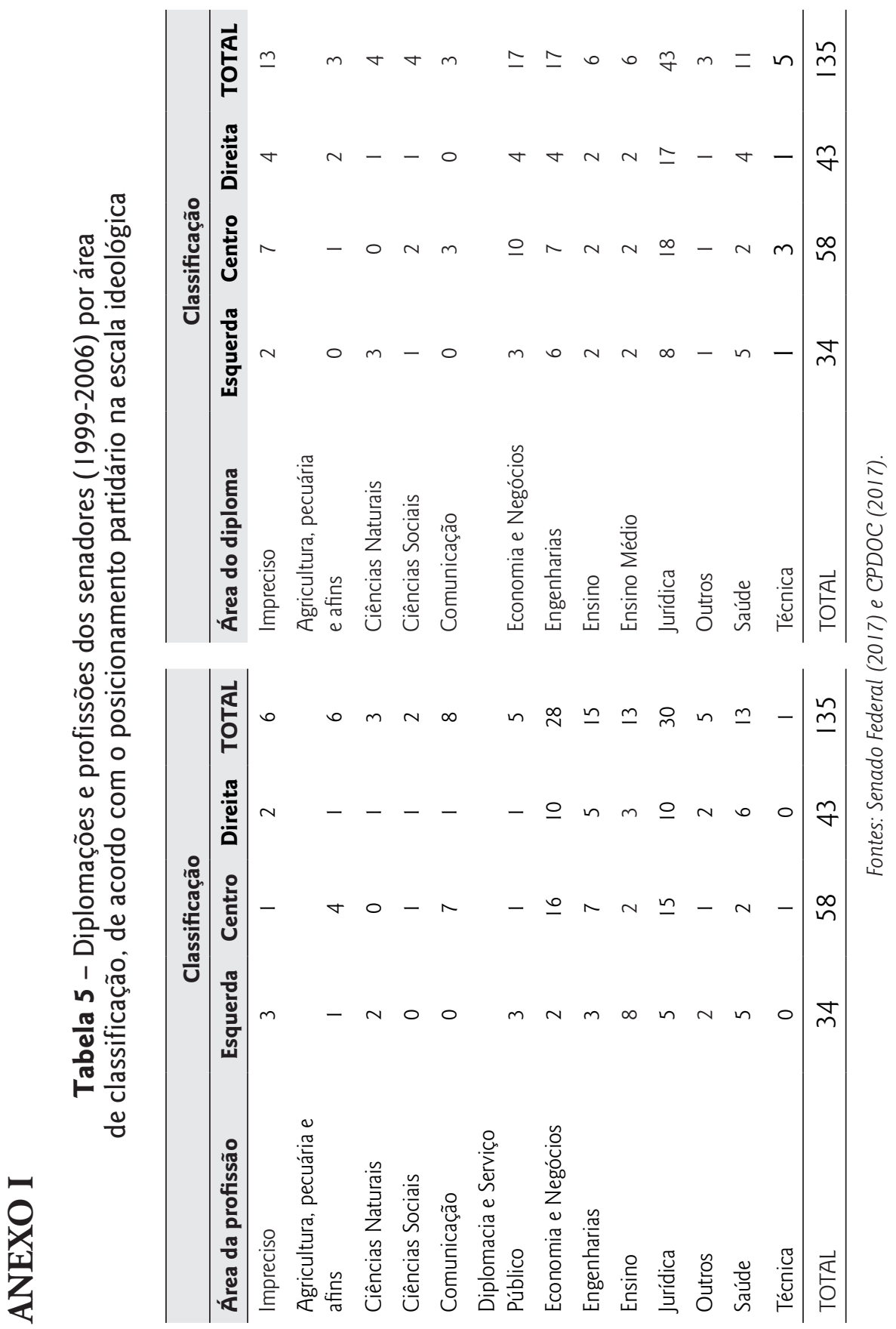

